Psychological Medicine, 1979, 9, 205-206

Printed in Great Britain

\title{
EDITORIAL
}

\section{Research in psychiatry: a view from general medicine ${ }^{1}$}

If there is too little research in psychiatry, and I find no difficulty in accepting this view, then causes and possible solutions deserve examination. At a time when knowledge of the function of the human brain is advancing rapidly in the basic sciences of physiology, pharmacology and biochemistry, the clinical counterpart is not. When recent Nobel Prizes in medicine have been awarded for, on the one hand, a combination of physiology, biochemistry and endocrinology of the brain (Schally and Guillemain), and on the other, for animal behavioural studies (Lorenz and Tinbergen), it is at present difficult to imagine a similar achievement in the field of psychiatry with the lead being taken by anyone with a psychiatric training. I shall not attempt to go into possible historical reasons for this situation but shall look at the present.

Research is carried out for various reasons, not all with equal emphasis, and I would give prime place to natural curiosity allied to a personal ambition to make an individual contribution. This carries with it a refusal to accept the stated obvious, the authoritative view, and I wonder if there is too little of this quality about in clinical psychiatry. Presumably the exceptional students do not enter the field and there is much past evidence, either from student surveys or from counting the number of graduates who take up psychiatry, that there is both a quantitative and qualitative deficiency. This is supported by the derivation of registrars and senior registrars of whom one half or more come from abroad. While other branches of medicine have a large number of foreign graduates at registrar level, this is not so at the senior level. Why do undergraduates enter any particular branch of medicine? Conjecture is easy and fallible, but surely they must see people practising and investigating the subject in a way they can admire if they are themselves to enter it. Therefore the state of academic psychiatry in the undergraduate schools needs examination. It is really only in the last ten years that such departments have developed in number, but in relation to large clinical loads, a professor and two lecturers may well be overwhelmed by the clinical and teaching tasks and completely unable to achieve research. Furthermore, the research experience and training in departments of psychiatry is not great. The subject depends very much on those not only with ideas, but able to make use of all the new developments in the basic sciences with confidence born of adequate training. They are the bridge men so important in every medical subject who bring together the purely clinical with the basic science for mutual enrichment. The path which the budding psychiatric research worker must follow at present is very long, and may include periods in general medicine as well as psychiatry in order to gain those paper qualifications regarded as indispensable in our regimented times and accreditation committees. To be fair, the Royal College of Psychiatrists does give some dispensation for time spent in research but it would not be surprising if many were deterred.

If this analysis is even approximately correct, what are the solutions? First, the most suitable academic departments in undergraduate schools must be strengthened by posts which would liberate time to give opportunity for investigation. Centres of active research do attract students and would provide the basis for future recruitment. Opportunity to provide joint enterprises between basic science departments and departments of psychiatry will depend on the creation of such new posts. Despite previous pessimism, there is money available if the right sort of propositions are brought forward for consideration, and various bodies have the problem of knowing how to make their funds available in the most effective manner. The route to psychiatric qualification and recognition should be made as easy as possible for those who have real research talent, and while recognizing the need for clinical experience, the emphasis must be shifted readily in deserving cases, and this requires that the Royal College of Psychiatrists should declare this quite clearly to be its policy.

If action is not taken now, clinical psychiatry will lag even further behind in application of all the

' Address for correspondence: Professor W. S. Peart, F.R.S., Medical Unit, St Mary's Hospital, London W2. 
brilliant advances being made in the relevant basic sciences. In medicine as a whole we have had longer to bring about this marriage; much is needed to improve that situation, but events have moved so fast in knowledge of the brain and its functions that urgency should be in the air. Otherwise, I fear that clinical psychiatry may rest in that uncomfortable state where its practitioners are regarded as purveyors of mumbo-jumbo at the worst and of brilliant dialectics at the best, and this is not attractive to the students on whom rests the future. While my analysis may be biased and even wrong headed, there is no doubt that no one should be happy with the present state. If ever there was a time in the development of a subject where the needs could be seen clearly, that time is now, and all those concerned in their subject should move optimistically and expeditiously.

W. S. PEART 